\title{
Design of graphene oxide/gelatin electrospun nanocomposite fibers for tissue engineering applications
}

Received 00th January 20xx, Accepted 00th January 20xx DOI: $10.1039 / \times 0 \times x 00000 x$ www.rsc.org/

\author{
Sakthivel Nagarajan ${ }^{\mathrm{a}, \mathrm{b}}$, Céline Pochat-Bohatier ${ }^{\mathrm{a}}$, Catherine Teyssier ${ }^{\mathrm{c}}$, Sébastien Balme ${ }^{\mathrm{a}}$, Philippe \\ Miele $^{a}$, Narayana Kalkura ${ }^{b}$, Vincent Cavaillès ${ }^{c}$ and Mikhael Bechelany ${ }^{\text {ta }}$
}

Gelatin is a biodegradable, nontoxic and biocompatible biopolymer. The biomedical application of un-crosslinked gelatin is limited, due to poor mechanical strength and high solubility. Hence, organic 2D graphene oxide (GO) nanosheets are used as reinforcing agents to enhance the mechanical properties. The $\mathrm{GO}$ exfoliation in gelatin is confirmed using $\mathrm{X}$-ray diffraction (XRD) analysis. The GO reinforcement enhances Young modulus (E) by $70 \%$ and tensile stress is also significantly improved. Moreover, the fibrous cross-linked electrospun mats are stable in phosphate buffered saline solution. The cell attachment and proliferation of the ESM are evaluated with human osteosarcoma cells (HOS) and the ESM is found to be biocompatible. However, the expression of osteoblast genes decreases with increasing GO incorporation. This report demonstrates that GO with high degree of oxidation, effectively reinforces and enhances the mechanical properties of the gelatin fibers. Also, increasing the concentration of GO does not show any significant influence on cell viability and cell attachment even though the expression of osteoblast gene is affected.

\section{Introduction}

Developing biodegradable, nontoxic polymeric composites is a focused area of tissue engineering field in order to replace metal and alloy based materials, which show adverse effects by releasing metal ions due to corrosion in body fluids $\underline{1}, \underline{2}$. Synthetic polymers are the most widely used alternative to the metal based implants. These polymers could release toxic fragments due to degradation $\frac{3-5}{}$ or chemical additives. Hence, biopolymers based materials such as collagen and cellulose are concerned materials for biomedical applications, due to high mechanical properties in native form $\frac{6-8}{}$. However, the chemical processes during extraction of biopolymers, like polysaccharides or proteins, alter their native forms and decreases their mechanical properties. Improving the mechanical properties of such biopolymers is essential in order to develop novel materials for tissue engineering applications $\underline{9}$ 10 .

Gelatin is obtained by the acid or basic hydrolysis of collagen. Its structure is composed by the repeating sequences of glycine$X-Y$ triplets where $X$ and $Y$ are frequently proline and hydroxyproline amino acids. These sequences are responsible for the triple helical structure of gelatin and its ability to form gels. Gelatin is highly degradable by the collagenase enzymes. It has low antigenicity in comparison to collagen and the degradation products of gelatin are highly biocompatible $\underline{11}, \underline{12}, \underline{13}$

\footnotetext{
a. Institut Européen des Membranes, UMR 5635 Université Montpellier, CNRS, ENSCM, Place Eugene Bataillon, F-34095 Montpellier cedex 5, France

b. Crystal Growth Centre, Anna University, Chennai, India, 600025.

c. IRCM, Institut de Recherche en Cancérologie de Montpellier, INSERM U1194,

Université Montpellier, Montpellier F-34298, France

+ Corresponding authors: Mikhael Bechelany, mikhael.bechelany@univ-montp2.fr.
}

Hence, gelatin with different morphologies (i.e. microspheres, electro spun fibers, hydrogels and polymeric nanoparticles) is widely studied for gene, drug and protein delivery $\underline{14-18}$. The development of gelatin based polymeric composites for tissue engineering applications is highly essential. However, their solubility and their poor mechanical properties still limit their applications.

$\mathrm{GO}$ is a 2 dimensional nanomaterial obtained by the oxidative exfoliation of graphite. GO shows a high surface area, 1 TPa of Young's modulus and $130 \mathrm{GPa}$ of intrinsic tensile strength $\underline{19}$. These properties make GO widely employed as a drug carrier and adsorbent $\underline{20}, \underline{21}$. The presence of polar functional groups (-OH, $-\mathrm{COOH},-\mathrm{CHO}$ and epoxides) in $\mathrm{GO}$ allows its good dispersion in hydrophilic polymers and the effective reinforcement that enhances their mechanical properties. Recent studies clearly evidenced that low concentrations of $\mathrm{GO}$ are nontoxic and biocompatible in comparison with single wall carbon nanotubes $\underline{22}, \underline{23}, \underline{24}$. Chaudhary et al. reported that GO-polycaprolactone is a suitable system for the regeneration of skeletal muscle tissue from human mesenchymal stem cells $\underline{25}$. Murray et al. reported that $\mathrm{GO}$ based polymeric composites are biocompatible as observed on fibroblast cell growthㄹ. $\underline{26}$. is also employed for the fabrication of glucose based biosensor and shown to be biocompatible using retinal pigment epithelium cells $\underline{27}$. Robinson et al. quantified the optimal concentration of covalently functionalized GO against glioblastoma cell lines $\underline{28}$. The concentration dependent biocompatibility of GO with HeLa cells proved that $\mathrm{GO}$ is a suitable candidate for biomedical applications as well $\underline{29}$.

Mimicking and synthesizing extra cellular matrix (ECM) like scaffolds are very essential for the regeneration of damaged 
tissues. The scaffolds facilitate the diffusion of growth factors and proteins and provide support for cell proliferation. The submicron polymeric electro spun fibers are potential candidates, due to the biomimetic nature of the fibrous 3D ECM like structure, their high surface area and their porous nature $\underline{30}$. Mesenchymal cells seeded on PCL ESM showed enhanced alkaline phosphatase activity, collagen I deposition and rigid bone like appearance $\underline{31}$. Mesenchymal stem cells seeded ESM gave excellent led to efficient repair of cartilage defects in vivo ${ }^{32}$. Li et al. reported that ESM are very helpful for the anisotropic alignment of cells $\underline{33}$. The aligned fibers seeded with mesenchymal stem cells showed enhanced ECM formation and high mechanical properties in comparison with nonaligned fibers $\underline{34}$. These results clearly depict the potentiality of ESM for tissue engineering applications. Gelatin/GO based films and 3D scaffolds have been prepared by various researchers and their physical properties have been analyzed $35-39$. Zhan et al. and Jalaja et al. prepared the GO reinforced gelatin ESM and briefly analyzed the physical properties $\underline{40}, \underline{41}$.

In this report, Graphite oxide is first synthesized with a high degree of oxidation in order to favor interactions with gelatin amino acids $\frac{42}{2}$. The highly oxidized $\mathrm{GO}$ is then inserted as mechanical filler in the gelatin biopolymer and used for the fabrication of nano composite ESM which are then stabilized with glutaraldehyde (GTA). The unreacted GTA is neutralized with glycine. This report mainly focuses in the tissue engineering aspects and elaborately analyses ESM biocompatibility using the HOS osteosarcoma cell line. The influence of different $\mathrm{GO}$ concentrations incorporated in gelatin fibers is monitored on cell attachment, cell proliferation and gene expression.

\section{Experimental}

\section{Materials}

The Gelatin type A (48722-500G-F) from porcine skin (gel strength170-195 g Bloom), glacial acetic acid, ethanol and 25\% glutaraldehyde (GTA) (G6257), phosphoric acid (W290017), sulfuric acid (258105), graphite (28286), potassium permanganate (223468), hydrogen peroxide (31642), are purchased from Sigma Aldrich and used without further purification.

\section{Synthesis of Graphite oxide}

The graphite oxide is synthesized as reported elsewhere $\underline{42}$ Briefly, $3 g$ of graphite is dispersed in sulfuric acid / phosphoric acid mixture (4:1 volume ratio). Potassium permanganate crystals $(18 \mathrm{~g})$ are added gradually to the mixture for graphite oxidation. The mixture is stirred for 3 hours and $3 \mathrm{~mL}$ of hydrogen peroxide is added. The resultant mixture is centrifuged at $6000 \mathrm{rpm}$ for 10 minutes. The Graphite oxide precipitates from the centrifugation are washed with $250 \mathrm{~mL}$ of $30 \%$ hydrochloric acid and then with $200 \mathrm{~mL}$ of $96 \%$ ethanol and finally dried at $60^{\circ} \mathrm{C}$.

\section{Preparation of electrospinning solution}

A $20 \%$ gelatin solution is prepared by dissolving gelatin in glacial acetic acid under magnetic stirring at $60^{\circ} \mathrm{C}$ for 2 hours. Graphite oxide powders (0.01, 0.1 and $1 \%$ weight/volume) are added to gelatin solutions and treated with an ultrasonic probe system (SONOPULS HD 3100) for 15 minutes ( 1 second pulse on and 0.5 second off) with $60 \%$ amplitude to exfoliate the graphite oxide. The resultant dispersion is centrifuged at $500 \mathrm{rpm}$ for 30 minutes to obtain the stable dispersion of gelatin/GO in the supernatant. The uniform dispersion exfoliated GO was obtained and used for electrospinning.

\section{Electrospinning of gelatin/ GO fibers}

The stable gelatin/GO dispersion obtained from the centrifugation is loaded in a $10 \mathrm{~mL}$ syringe. A syringe pump (KDS 100 ) is used to feed the solution through $0.7 \mathrm{~mm}$ diameter needle, with the flow rate of $0.5 \mathrm{~mL} \mathrm{~h}^{-1}$. The electrospinning system is operated at $25 \mathrm{kV}$ by using HPx 600605 generator (Physical Instruments) ${ }^{43}$. A piece of aluminum foil wrapped around the rotating unit at $400 \mathrm{rpm}$ is used to collect the fibers. The electrospinning is carried out at $35^{\circ} \mathrm{C}$ at ambient air atmosphere. The fibers prepared using $20 \%$ gelatin are denoted as OUGO and the nanofibers prepared using various graphite oxide/gelatin weight fraction such as $0.01,0.1$ and $1 \%$ are referred as $0.01 \mathrm{UGO}, 0.1 \mathrm{UGO}$ and $1 \mathrm{UGO}$ respectively.

\section{Cross-linking of ESM}

The collected mats are cut into uniform size of $5 \times 5 \mathrm{~cm}^{2}$, and dipped into a $0.25 \%$ glutaraldehyde (GTA) solution at $37^{\circ} \mathrm{C}$ for 4 h. The $0.25 \%$ GTA solution is prepared from $25 \%$ GTA stock solution using $96 \%$ ethanol as a solvent. The cross-linked fibers are separated out after $4 \mathrm{~h}$ and washed thrice with PBS (phosphate buffered saline). The unreacted GTA is neutralized with $10 \%$ glycine solution at $37^{\circ} \mathrm{C}$ for 12 hours. The washed samples are dried at $37^{\circ} \mathrm{C}$ for $24 \mathrm{~h}$. The cross-linked OUGO, 0.01 UGO, 0.1UGO and 1 UGO are denoted as 0CGO, 0.01CGO, $0.1 \mathrm{CGO}$ and 1 CGO respectively. In general, the cross-linked and uncross-linked ESM will be denoted as CGO and UGO respectively.

\section{Characterization of uncross-linked (UGO) and cross-linked $\operatorname{ESM}(\mathrm{CGO})$}

The FTIR (Nexus) spectrum of cross-linked ESM is recorded in the frequency range of $600-4000 \mathrm{~cm}^{-1}$ using attenuated total reflection (ATR) accessory. The FTIR spectrum is recorded at 1 $\mathrm{cm}^{-1}$ resolution and the averaged signals are recorded. The XRD patterns of gelatin/ GO ESM are recorded using CuK $\alpha$ radiation, $2 \Theta$ range of $3-70^{\circ}$ with a scan speed of $2^{\circ} \mathrm{min}^{-1}$, and a step rate of $0.02^{\circ}$ per second, using the PANalytica Xpert powder XRD system.

The fibrous morphology of the UGO and CGO ESM is observed using HITACHI 54800 scanning electron microscopy (SEM) system. The mats are coated with platinum using ion sputter coater before observing the morphology by SEM. The size of the fibers is measured at various fibers using image $J$ software and the results are averaged. The one way ANOVA statistical analysis was performed.

The mechanical properties of the CGO ESM are analyzed using extensional rheology. The analysis are carried out using rheometer MCR301 (Anton Paar) and using the Universal 
Extensional Fixture UXF12. Dynamic Mechanical Analyses in tension are performed until the break of the samples in the elongation range $0.001-300 \%$ with a frequency of $1 \mathrm{~Hz}$. The temperature of the system is controlled at $25^{\circ} \mathrm{C}$ with CTD180 Peltier system. The samples are cut into uniform dimension of $4 \times 1 \mathrm{~cm}^{2}$ for the experiments. The experiments are repeated for three times and average results are reported. The ESM thickness is measured using the thickness gauge (Mitutoyo). The thickness is measured at 10 places and average results are used. Young Modulus is determined at low deformation in the elastic region of the stress-strain curve.

\section{Cell Culture}

Human HOS osteosarcoma cells (Institute of Functional Genomics (IGF), Montpellier, France) are cultured in DMEM Dulbecco's Modified Eagle Medium - (Gibco 31331-028) along with the supplements of $10 \%(\mathrm{~V} / \mathrm{V})$ Fetal Bovine Serum (FBS) (Eurobio CVFSVF00-01) and $1 \%(V / V)$ penicillin/Streptomycin (Gibco $15140-122$ ) at $37^{\circ} \mathrm{C}$ in $5 \% \mathrm{CO}_{2}$. The cells are maintained in $10 \mathrm{~cm}$ diameter Petri dishes and passaged using $0.05 \%$ Trypsin-EDTA (Gibco 25300-054).

\section{Cell adhesion}

The cells ( $3 \times 10^{3}$ cells) are seeded on the CGO ESM and cultured for various period ( 1,4 and 8 days). The ESM is recovered and cells are fixed with $4 \%$ formaldehyde and washed twice with PBS. Cell nuclei are stained with Hoechst 33342 (1/1000 dilution $V / V$ in PBS) for 20 minutes. The ESM are washed with PBS and mounted for cell observation using a fluorescent microscope (Leica, DM6000).

\section{Cell viability assay}

The ESMs are cut into $6 \mathrm{~mm}$ diameter circles and sterilized for 20 minutes under UV light exposure. Cells $\left(1 \times 10^{3}\right.$ cells/well) are seeded on the plates and the sterilized samples are placed over the cells which are previously allowed to attach for 24 hours. The sterilized samples are placed over the cells which are then cultured for 8 days. Cell viability is analyzed using MTT (3-(4,5Dimethylthiazol-2-yl)-2,5-diphenyl tetrazolium bromide) assay. Briefly, cell culture medium is removed and replaced by $100 \mu \mathrm{L}$ of culture medium containing $0.05 \mathrm{mg} \mathrm{mL}^{-1}$ of $\mathrm{MTT}$ solution incubated for $4 \mathrm{~h}$. Purple colored formazan crystals are dissolved with $100 \mu \mathrm{L}$ of DMSO (BDH prolab 23486.297) and the absorbance of the solution is recorded at $560 \mathrm{~nm}$ using a Multiskan plate reader (Thermos, USA)

\section{Real-time qPCR}

Total RNA is extracted from cells cultured on the materials for 8 days using the Quick RNA ${ }^{\mathrm{TM}}$ Miniprep kit (Zymo Research) according to the manufacturer's instructions. The cDNA synthesis is carried out using $1 \mu \mathrm{g}$ of RNA and the qScript cDNA Master mix (Quanta Bioscience). The expression of mRNA is quantitatively determined by real time PCR (qPCR), by using the 2X SYBR Green Master Mix (VWR) with the Light Cycler 480 (Roche Applied Science). The experiment is carried out in a final reaction volume of $10 \mu \mathrm{l}$, containing $0.5 \mu \mathrm{l}$ of each primer (25 $\mu \mathrm{M}), 5 \mu \mathrm{l}$ of the SYBR Green Master mix, $2.5 \mu \mathrm{l}$ of $\mathrm{H}_{2} \mathrm{O}$, and $2 \mu \mathrm{l}$ of the cDNA template at a 1:5 dilution. After pre-incubation at $95^{\circ} \mathrm{C}$, runs corresponding to 40 cycles of 15 seconds at $95^{\circ} \mathrm{C}, 45$ seconds at $60^{\circ} \mathrm{C}$, and 30 seconds at $72^{\circ} \mathrm{C}$, are followed by melting curves analysis to eliminate non-specific amplification products. The expression of mRNA levels is normalized to TBP mRNA and is expressed relative to OCGO values. The primer sequences are listed in the Table 1.

Table 1. Sequence of primers used for mRNA quantification by RT-qPCR

\begin{tabular}{ccc}
\hline Primer & Forward sequence & Reverse sequence \\
\hline $\begin{array}{c}\text { Collagen I } \\
\text { (Col I) }\end{array}$ & $\begin{array}{c}\text { AGGGCCAAGACGAAGACA } \\
\text { TC }\end{array}$ & $\begin{array}{c}\text { AGATCACGTCATCGCACA } \\
\text { ACA }\end{array}$ \\
\hline $\begin{array}{c}\text { Osteoponti } \\
\mathbf{n} \text { (OSPN) }\end{array}$ & $\begin{array}{c}\text { GTGCCATACCAGTTAAACA } \\
\text { G }\end{array}$ & CTTACTTGGAAGGGTCTGTG \\
\hline RUNX2 & $\begin{array}{c}\text { CCTAAATCACTGAGGCGGT } \\
\text { C }\end{array}$ & CAGTAGATGGACCTCGGGAA \\
\hline SPARC & $\begin{array}{c}\text { GAAAGAAGATCCAGGCCC } \\
\text { TC }\end{array}$ & CTTCAGACTGCCCGGAGA \\
\hline SP7 & $\begin{array}{c}\text { CACAGCTCTTCTGACTGTC } \\
\text { TG }\end{array}$ & $\begin{array}{c}\text { CTGGTGAATGCCTGCATGG } \\
\text { AT }\end{array}$ \\
\hline
\end{tabular}

\section{Results and discussion}

In order to analyze the efficient oxidation of graphite and the exfoliation of GO inside the gelatin matrix, XRD patterns of the pure Graphite oxide, and CGO ESM with different concentrations of GO are recorded (Figure 1). The absence of triple helix peak at $1.1 \mathrm{~nm}$ and the presence of broadband observed between 15 and $25^{\circ}$ for gelatin evidenced the denatured secondary structure of gelatin and shows its amorphous nature. The major plane (002) observed at $2 \Theta$ of $10^{\circ}$ clearly depicts the presence of graphite oxide. The (002) plane of graphite oxide disappears in the Gelatin/GO ESM confirming the exfoliation of graphite oxide inside the gelatin matrix $\underline{44}$. The hydrophobic interaction between gelatin and $\mathrm{GO}$ and the amorphous structure of gelatin also favors the GO dispersion in gelatin matrix. The $\mathrm{GO}$ is amphoteric in which hydrophilic property comes from the polar groups (carboxylates, hydroxyl groups, and epoxide) and hydrophobic property from the GO backbone (unoxidized aromatic groups)45, 46. The gelatin exhibits hydrophilic property but also consists of hydrophobic residues from amino acids (leucine, isoleucine and valine) ${ }^{47}$. 


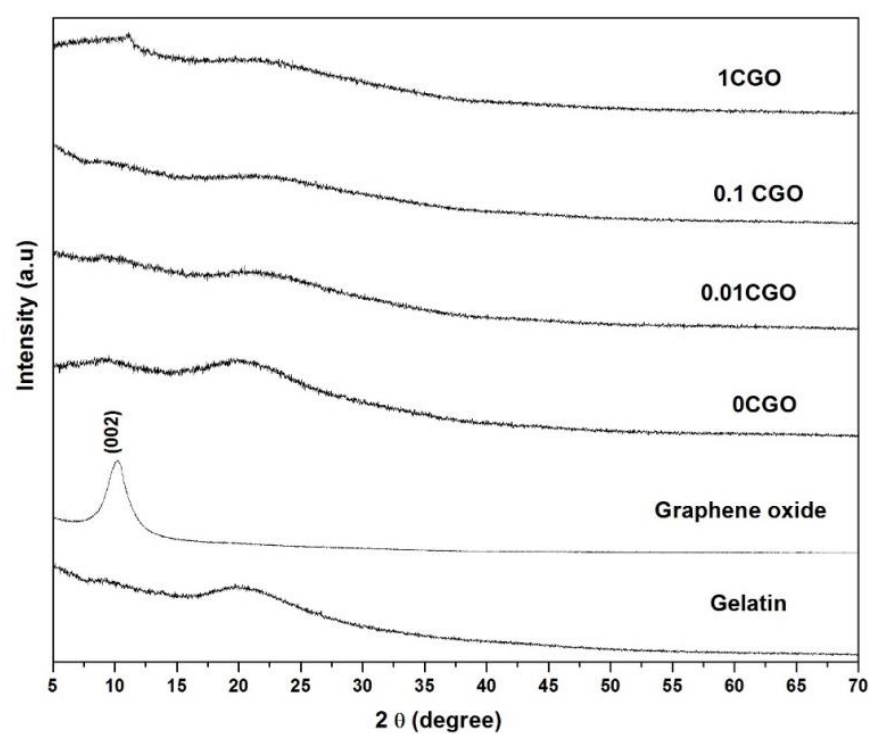

Figure 1. XRD patterns of the CGO ESM with different concentrations of $\mathrm{GO}$.
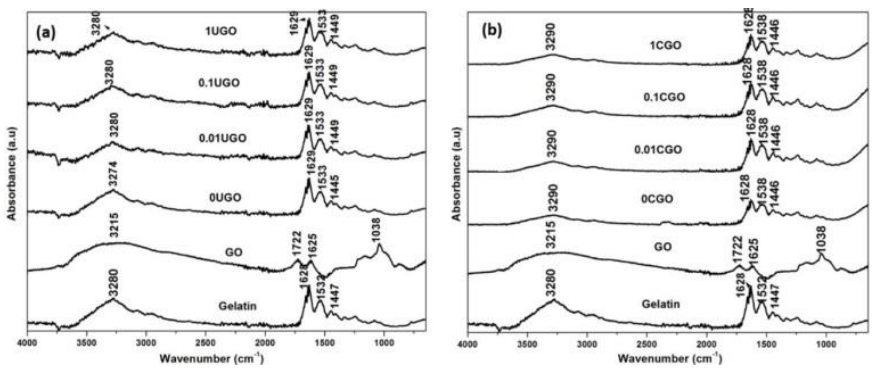

Figure 2. FTIR spectrum of UGO (a) and CGO (b) ESM.

The interaction of GO with gelatin and the effect of gelatin crosslinking are analyzed by FTIR spectroscopy and the FTIR spectra of UGO and CGO ESM are shown in Figure 2. The peak observed at $3280 \mathrm{~cm}^{-1}$ for UGO ESM corresponds to amide $A$ The shift $\left(10 \mathrm{~cm}^{-1}\right)$ as well as the decrease of peak intensity also evidences the crosslinking. The characteristic stretching vibration of Amide I, II and III are observed at 1629, 1533-1538 and $1445-1449 \mathrm{~cm}^{-1}$ respectively in CGO and UGO ESM $\underline{48}$. The carbonyl stretching positioned at $1722 \mathrm{~cm}^{-1}$ and aromatic $\mathrm{C}=\mathrm{C}$, C-O epoxy stretching observed at 1625 and $1038 \mathrm{~cm}^{-1}$ respectively also evidence graphite oxidation $\underline{49}$.

The mechanical properties (Young's modulus, strain and stress at break) of gelatin ESM and GO reinforced gelatin ESM are listed in Table 2. The Young's modulus is calculated from the slope of the linear elastic region of stress-strain curve at low deformation. However, the tensile stress and strain at break are determined from the point at which load failure is observed. The stiffness and the strength of the materials are therefore enhanced with $\mathrm{GO}$ addition (The elastic modulus and tensile stress at break of GO reinforced ESM increased by $70 \%$ and $200 \%$ respectively in comparison to gelatin ESM). The improvement of mechanical properties with the increase of $\mathrm{GO}$ concentration depicts that the exfoliated GO reinforces efficiently the gelatin matrix. This likely comes from the hydrogen bonding between carboxylates, alkoxide groups and hydroxyl groups of GO and the Amide A of gelatin (evidenced from FTIR).

The fibrous morphology of the UGO ESM, the change of the fiber morphology during crosslinking and the stability of ESM in aqueous glycine solution are recorded with scanning electron microscopy (SEM) and shown in the Figure 3. The SEM micrographs show the uniform fibers without beads when increasing the GO concentration. The fiber diameter was measured at 15 positions using Image $\mathrm{J}$ software and the results are averaged. The diameter of gelatin and GO reinforced gelatin fibers ranges between 0.9 and $2.2 \mu \mathrm{m}$. The crosslinking does not influence the fiber diameter significantly $(p>0.05)$. The crosslinking leads to the fusion of fibers at the fiber junctions and the fibers are tightly packed compared to UGO ESM. The cross-linked fibers maintain their fibrous morphology and the porous structure, which is suitable for infiltration of nutrients and biomolecules.

Table 2. Tensile strength, elastic modulus and tensile strain of CGO ESM

\begin{tabular}{cccc}
\hline & $\begin{array}{c}\text { Young's Modulus (E) } \\
\text { (GPa) }\end{array}$ & $\begin{array}{c}\text { Strain at break } \\
\text { (\%) }\end{array}$ & $\begin{array}{c}\text { Stress at break } \\
\text { (MPa) }\end{array}$ \\
\hline 0CGO & $1.70 \pm 0.16$ & $0.73 \pm 0.13$ & $2.82 \pm 0.16$ \\
\hline $\mathbf{0 . 0 1 C G O}$ & $1.80 \pm 0.19$ & $0.72 \pm 0.02$ & $4.06 \pm 0.32$ \\
\hline $\mathbf{0 . 1 C G O}$ & $2.30 \pm 0.41$ & $1.31 \pm 0.22$ & $4.01 \pm 0.13$ \\
\hline 1CGO & $2.90 \pm 0.01$ & $6.26 \pm 0.13$ & $8.67 \pm 0.58$ \\
\hline
\end{tabular}

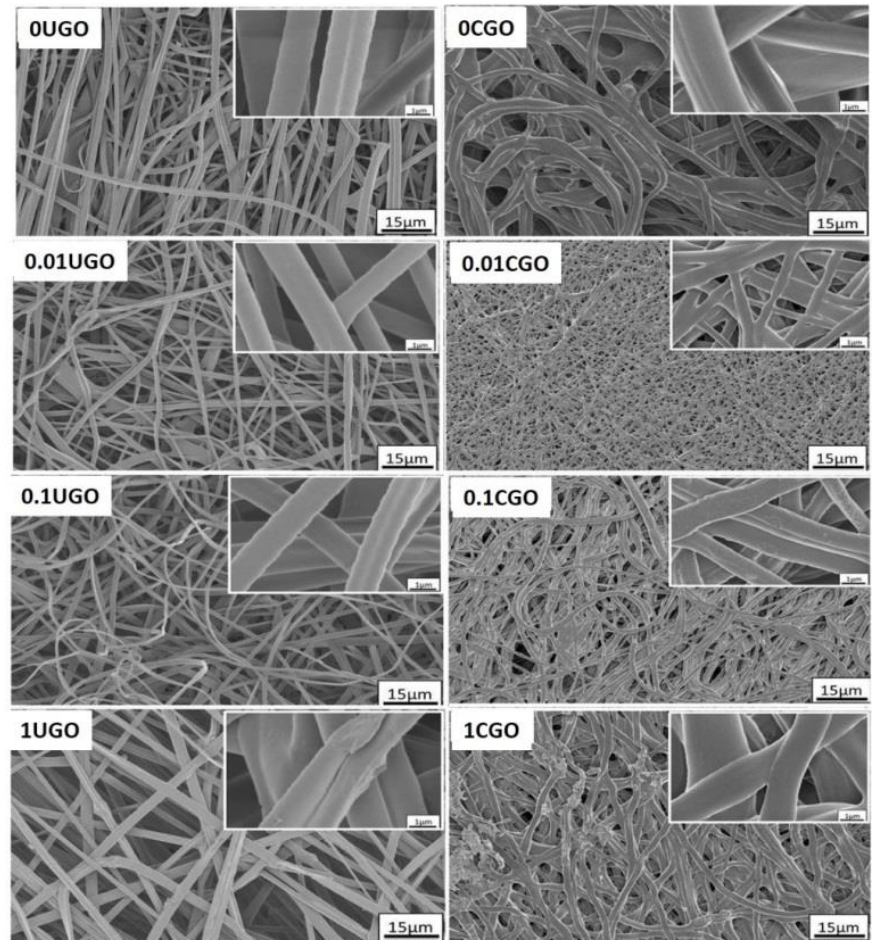

Figure 3. SEM micrographs of the UGO and CGO ESM (in inset a zoom of fiber).

To assess the gelatin and gelatin/GO ESM biocompatibility, cell attachment and proliferation on the different ESMs are first monitored using osteosarcoma cell lines. Since the cross-linked gelatin is strongly auto fluorescent, the staining of the actin filament is limited $\underline{50}$. Hence the nuclei is stained with Hoechst 
33342.a (Figure 4). On all samples, HOS cell attachment is detected after 24 hours and a significant proliferation is observed after 4 and 8 days. Cell attachment and proliferation on the different GO concentration reinforced ESM do not appeared significantly different in comparison with the OCGO, which suggest that $\mathrm{GO}$ addition to the gelatin does not affect ESMs biocompatibility.

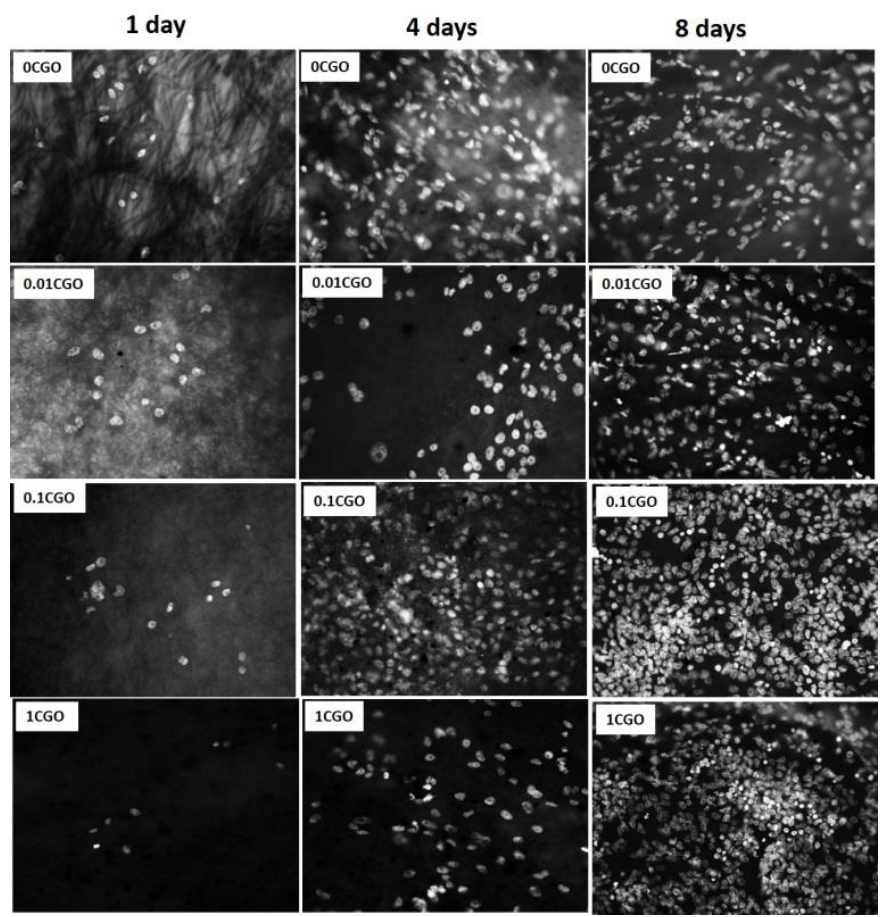

Figure 4. Attachment and proliferation of HOS cells on CGO ESM (Nuclei stained with Hoechst 33342).

To further monitor differentiation of HOS cells grown on the ESMs, the expression of osteoblast genes such as Collagen I (Coll), Osteopontin (OSPN), Runx2, SPARC and SP7 was analyzed by RT-qPCR. The Col I is the major organic content of bone and forms the ECM. Ostepontin is the non-collagenous protein which plays important role in bone remodeling and adhesion of bone cells on bone surface. RUNX2 supports to upregulate the osteoblast differentiation. SPARC (Osteonectin) is the glycoprotein essential for bone mineralization. Finally, SP7 is the Zinc finger-containing transcription factor which is essential for osteoblast differentiation. Except for SP7, the osteoblast gene expression significantly decreased with the increasing of GO concentrations in comparison to OCGO (Figure 5). The collagen I and OSPN expression is down regulated, whereas, SP7 gene is not significantly affected by GO concentration. This is probably due to the oxidative stress exhibited by the GO on the cells, which may induce DNA damage and alter gene expression $\underline{51}$. The down regulation of osteoblast genes can be controlled by the immobilization of growth factors like bone morphogenetic proteins $\underline{52}$.

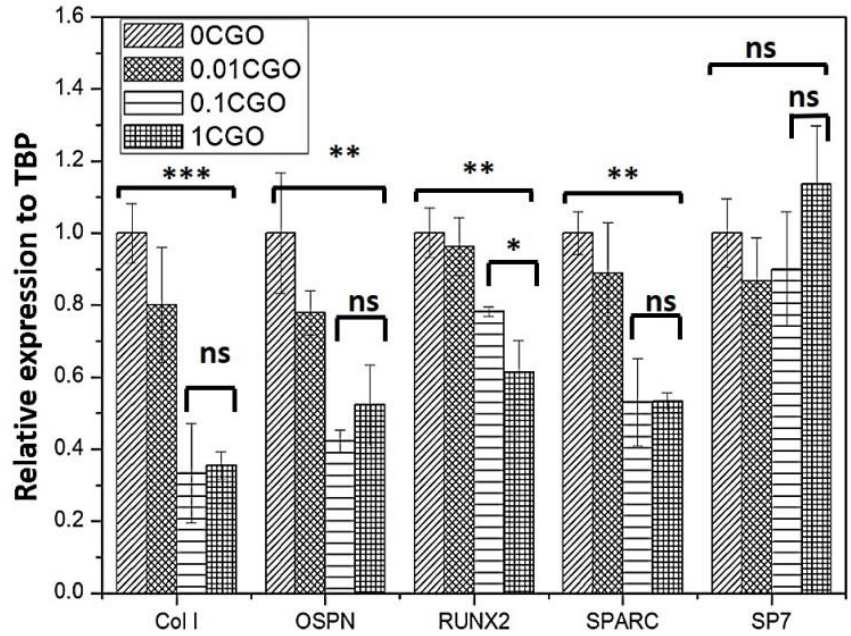

Figure 5. Gene expression of HOS cells grown on CGO ESM $(p<0.05=*, \quad p<0.005=* *, \quad p<0.0005=* * *, \quad p>0.05 \quad n s=n o$ significance).

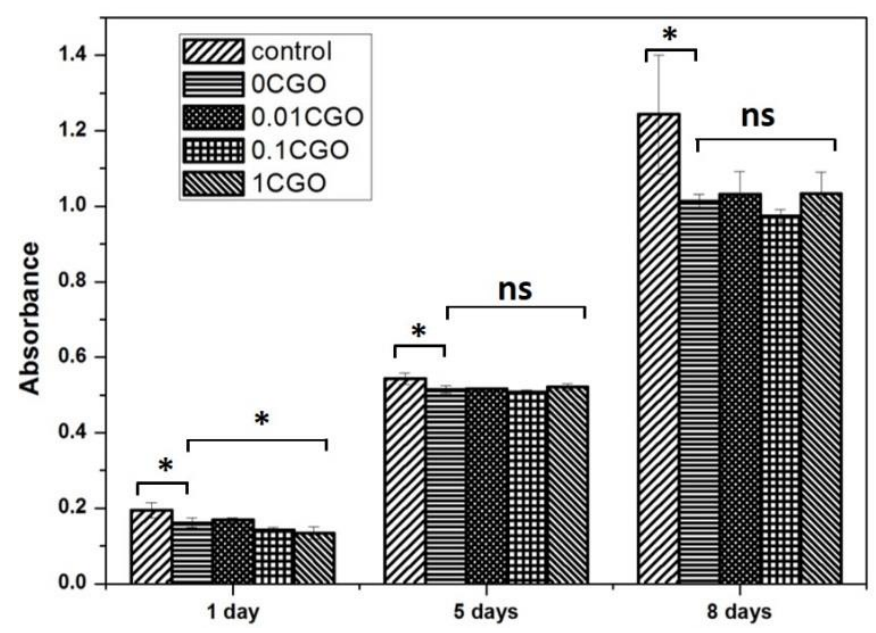

Figure 6. Cytotoxicity of CGO ESM.

Finally, the influence of increasing concentration of GO on the gelatin ESM biocompatibility was recorded using MTT assay (Figure 6). The HOS cells grown in the presence of CGO ESM at various periods are compared with cells grown without material (considered as the control sample). The unreacted GTA is strongly cytotoxic which crosslinks the $\mathrm{N}$-terminal amino groups of peptides, DNA with proteins and results to the cytotoxicity. Hence the unreacted aldehyde terminals are neutralized with glycine solution $\underline{53}$. The biocompatibility of the CGO ESM decreases in comparison with the control $(p<0.05)$, irrespectively of the GO concentrations. The long term contact ( 4 and 8 days) of the samples with the HOS cells also suggested that GO concentration does not affect the effect of the ESM on cell viability. However, biocompatibility of the OCGO decreased after 8 days in comparison to the control sample. This slight decrease in the biocompatibility of the ESM is probably due to the GTA cross linkers. Chang et al. reported that GO induced a cellular oxidative stress and decreased cell viability. The cytotoxicity of the GO is mainly size, concentration and surface charge dependent. Various studies also proved that 
functionalising (covalent, noncovalent, polymer wrapping, $\pi-\pi$ interaction) polymers with GO improved their biocompatibility $\underline{54}, \underline{55}$. Nevertheless, data shown in Figure 6 indicated that cell proliferation increases in comparison to 1 day which evidences that the influence of crosslinking is very low on cell viability. Altogether, these results clearly demonstrate that the modification of gelatin with GO does not significantly modify its biocompatibility.

\section{Conclusions}

In the present study, gelatin/ GO ESMs were synthesized. Chemical and structural characterizations demonstrate that the GO reinforces the gelatin biopolymer and leading to $70 \%$ increase in the Young modulus and $200 \%$ raise of the tensile stress in comparison with gelatin ESM. The CGO ESMs conserve their fibrous morphology and porous structure which allow cell attachment and proliferation. The GTA crosslinking induces a slight cytotoxicity of the ESM on HOS cells, however, the cell proliferation is not significantly affected. In addition, high GO concentrations decrease the expression of some osteoblast genes such as collagenase I and osteopontin. It clearly demonstrates that the $\mathrm{GO}$ induces concentration dependent impact on gene expression. These results shows that GO is a promising nanomaterial to improve the mechanical property of gelatin without affecting biocompatibility.

\section{Acknowledgements}

S. N. benefits of Svagaata Fellowship (Erasmus Mundus Program, European Union). This work was partially supported by the European Institute of Membrane by health project (Santé-P1S16).

\section{References}

1. D. Olmedo, M. M. Fernández, M. B. Guglielmotti and R. L. Cabrini, Implant Dentistry, 2003, 12, 75-80.

2. R. Pivec, R. M. Meneghini, W. J. Hozack, G. H. Westrich and M. A. Mont, The Journal of Arthroplasty, 2014, 29, 1-6.

3. M. S. Taylor, A. U. Daniels, K. P. Andriano and J. Heller, Journal of Applied Biomaterials, 1994, 5, 151-157.

4. O. Böstman and H. Pihlajamäki, Biomaterials, 2000, 21 2615-2621.

5. H. Park and K. Park, Pharmaceutical Research, 13, 17701776.

6. M. J. Buehler, Proceedings of the National Academy of Sciences of the United States of America, 2006, 103, 1228512290.

7. J. Howard, Mechanics of Motor Proteins and the Cytoskeleton, Sinauer Associates, Publishers, 2001.

8. T. Nishino, K. Takano and K. Nakamae, Journal of Polymer Science Part B: Polymer Physics, 1995, 33, 1647-1651.

9. S. Yunoki, T. Ikoma, A. Monkawa, K. Ohta, M. Kikuchi, S. Sotome, K. Shinomiya and J. Tanaka, Materials Letters, 2006, 60, 999-1002.
10. S.-B. Lee, J.-S. Kwon, Y.-K. Lee, K.-M. Kim and K.-N. Kim, Journal of Biomedical Materials Research Part B: Applied Biomaterials, 2012, 100B, 1935-1942.

11. A. O. Elzoghby, W. M. Samy and N. A. Elgindy, Journal of Controlled Release, 2012, 161, 38-49.

12. K. Mladenovska, E. F. Kumbaradzi, G. M. Dodov, L. Makraduli and K. Goracinova, International Journal of Pharmaceutics, 2002, 242, 247-249.

13. J. Liu, D. Meisner, E. Kwong, X. Y. Wu and M. R. Johnston, Biomaterials, 2007, 28, 3236-3244.

14. A. K. Gupta, M. Gupta, S. J. Yarwood and A. S. G. Curtis, Journal of Controlled Release, 2004, 95, 197-207.

15. V. DiTizio, C. Karlgard, L. Lilge, A. E. Khoury, M. W. Mittelman and F. DiCosmo, Journal of Biomedical Materials Research, 2000, 51, 96-106.

16. L. Silvio, R. G. Courteney-Harris and S. Downes, Journal of Materials Science: Materials in Medicine, 5, 819-823.

17. S. Nagarajan, L. Soussan, M. Bechelany, C. Teyssier, V. Cavailles, C. Pochat-Bohatier, P. Miele, N. Kalkura, J.-M. Janot and S. Balme, Journal of Materials Chemistry B, 2016, DOI: 10.1039/C5TB01897H.

18. Y. B. Choy, F. Cheng, H. Choi and K. Kim, Macromolecular Bioscience, 2008, 8, 758-765.

19. C. Lee, X. Wei, J. W. Kysar and J. Hone, Science, 2008, 321, 385.

20. X. Yang, Y. Wang, X. Huang, Y. Ma, Y. Huang, R. Yang, H. Duan and Y. Chen, Journal of Materials Chemistry, 2011, 21, 34483454.

21. R. Sitko, E. Turek, B. Zawisza, E. Malicka, E. Talik, J. Heimann, A. Gagor, B. Feist and R. Wrzalik, Dalton Transactions, 2013, 42, 5682-5689.

22. X. Zhang, J. Yin, C. Peng, W. Hu, Z. Zhu, W. Li, C. Fan and Q. Huang, Carbon, 2011, 49, 986-995.

23. K. Wang, J. Ruan, H. Song, J. Zhang, Y. Wo, S. Guo and D. Cui, Nanoscale Research Letters, 2011, 6, 8-8.

24. S. Gurunathan, J. W. Han, V. Eppakayala and J.-H. Kim, Colloids and Surfaces B: Biointerfaces, 2013, 105, 58-66.

25. C. Biswadeep, B. Debabrata, M. Lorenzo and P. Krishna, Biofabrication, 2015, 7, 015009.

26. E. Murray, S. Sayyar, B. C. Thompson, R. Gorkin lii, D. L. Officer and G. G. Wallace, RSC Advances, 2015, 5, 45284-45290. 27. Y. Liu, D. Yu, C. Zeng, Z. Miao and L. Dai, Langmuir, 2010, 26, 6158-6160.

28. J. T. Robinson, S. M. Tabakman, Y. Liang, H. Wang, H. Sanchez Casalongue, D. Vinh and H. Dai, Journal of the American Chemical Society, 2011, 133, 6825-6831.

29. Y.-K. Kim, M.-H. Kim and D.-H. Min, Chemical Communications, 2011, 47, 3195-3197.

30. W.-J. Li, C. T. Laurencin, E. J. Caterson, R. S. Tuan and F. K. Ko, Journal of Biomedical Materials Research, 2002, 60, 613621.

31. H. Y. Michael Shin, and Joseph P. Vacanti, Tissue Engineering, 2004, 10.

32. W.-J. Li, H. Chiang, T.-F. Kuo, H.-S. Lee, C.-C. Jiang and R. S. Tuan, Journal of Tissue Engineering and Regenerative Medicine, 2009, 3, 1-10. 
33. W.-J. Li, R. L. Mauck, J. A. Cooper, X. Yuan and R. S. Tuan, Journal of Biomechanics, 2007, 40, 1686-1693.

34. B. M. Baker and R. L. Mauck, Biomaterials, 2007, 28, 19671977.

35. C. Wan, M. Frydrych and B. Chen, Soft Matter, 2011, 7, 61596166.

36. N. Zhang, H. Qiu, Y. Si, W. Wang and J. Gao, Carbon, 2011, 49, 827-837.

37. S. Faghihi, A. Karimi, M. Jamadi, R. Imani and R. Salarian, Materials Science and Engineering: C, 2014, 38, 299-305.

38. Y. Piao and B. Chen, RSC Advances, 2016, 6, 6171-6181.

39. W. Wang, Z. Wang, Y. Liu, N. Li, W. Wang and J. Gao, Materials Research Bulletin, 2012, 47, 2245-2251.

40. J. Zhan, Y. Morsi, H. Ei-Hamshary, S. S. Al-Deyab and X. Mo, Journal of Biomaterials Science, Polymer Edition, 2016, 27, 385402.

41. K. Jalaja, V. S. Sreehari, P. R. A. Kumar and R. J. Nirmala, Materials Science and Engineering: C, 2016, 64, 11-19.

42. D. C. Marcano, D. V. Kosynkin, J. M. Berlin, A. Sinitskii, Z. Sun, A. Slesarev, L. B. Alemany, W. Lu and J. M. Tour, ACS Nano, 2010, 4, 4806-4814.

43. A. A. Chaaya, M. Bechelany, S. Balme and P. Miele, Journal of Materials Chemistry A, 2014, 2, 20650-20658.

44. X. Yang, Y. Tu, L. Li, S. Shang and X.-m. Tao, ACS Applied Materials \& Interfaces, 2010, 2, 1707-1713.

45. J. Kim, L. J. Cote, F. Kim, W. Yuan, K. R. Shull and J. Huang, Journal of the American Chemical Society, 2010, 132, 81808186.

46. M. H. Wahid, X. Chen, C. T. Gibson and C. L. Raston, Chemical Communications, 2015, 51, 11709-11712.

47. S.-Y. Lin, T.-F. Wu and H.-K. Tsao, Macromolecules, 2003, 36, 8786-8795.

48. S. Kim, M. E. Nimni, Z. Yang and B. Han, Journal of Biomedical Materials Research Part B: Applied Biomaterials, 2005, 75B, 442-450.

49. V. Loryuenyong, K. Totepvimarn, P. Eimburanapravat, W. Boonchompoo and A. Buasri, Advances in Materials Science and Engineering, 2013, 2013, 5.

50. B. Cai, L. Rao, X. Ji, L.-L. Bu, Z. He, D. Wan, Y. Yang, W. Liu, S. Guo and X.-Z. Zhao, Journal of Biomedical Materials Research Part A, 2016, DOI: 10.1002/jbm.a.35823, n/a-n/a.

51. Y. Liu, Y. Luo, J. Wu, Y. Wang, X. Yang, R. Yang, B. Wang, J. Yang and N. Zhang, Scientific Reports, 2013, 3, 3469.

52. W.-G. La, M. Jin, S. Park, H.-H. Yoon, G.-J. Jeong, S. H. Bhang, H. Park, K. Char and B.-S. Kim, International Journal of Nanomedicine, 2014, 9, 107-116.

53. R. O. Beauchamp, M. B. G. St Clair, T. R. Fennell, D. O. Clarke, K. T. Morgan and F. W. Karl, Critical Reviews in Toxicology, 1992, 22, 143-174.

54. V. Georgakilas, J. N. Tiwari, K. C. Kemp, J. A. Perman, A. B. Bourlinos, K. S. Kim and R. Zboril, Chemical Reviews, 2016, 116, 5464-5519.

55. M. Xu, J. Zhu, F. Wang, Y. Xiong, Y. Wu, Q. Wang, J. Weng, Z. Zhang, W. Chen and S. Liu, ACS Nano, 2016, 10, 3267-3281.

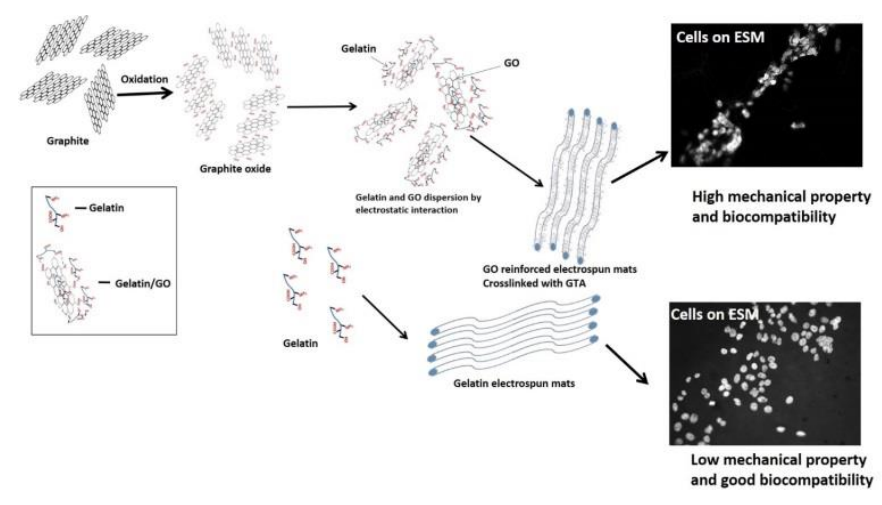

\section{Graphical Abstract}

